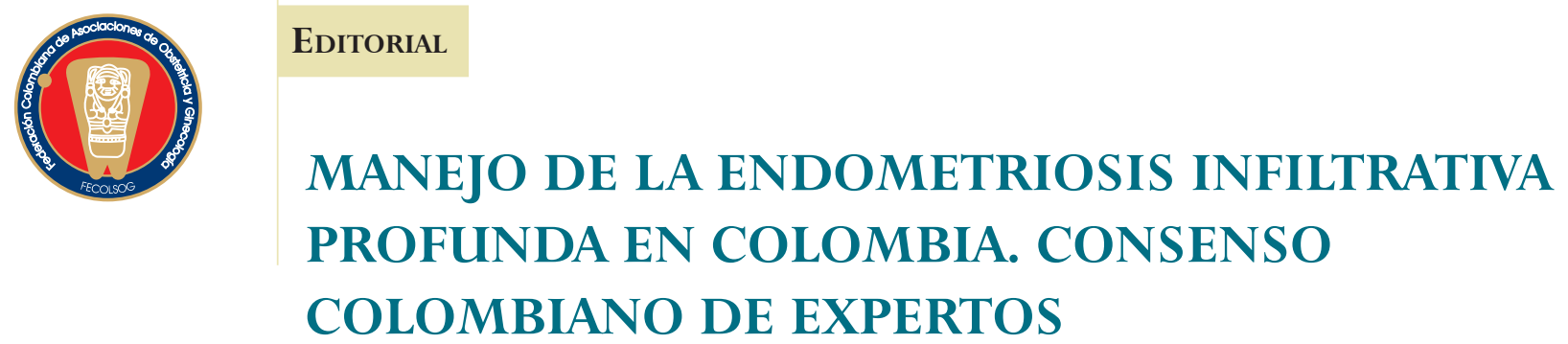

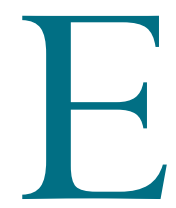
n el marco del pasado XXVIII Congreso Colombiano de Obstetricia y Ginecología que se realizó en Cartagena de Indias en mayo de 2012, se llevó a cabo la reunión denominada: "Consenso colombiano de expertos en endometriosis", a la que asistieron los miembros del Capítulo de Endoscopia Ginecológica de Fecolsog, reconocidos especialistas de las diversas regiones del país expertos en el tema, y los profesores internacionales que participaron en el Congreso con disertaciones sobre dicha enfermedad, entre ellos la doctora Liliana Mereu (Italia), el doctor Mauricio Abrao (Brasil), el doctor Francisco Carmona (España) y el doctor John Steege (Estados Unidos). Dicha reunión tuvo por tema académico único el "Manejo de la endometriosis infiltrativa profunda en Colombia”.

Como resultado de la reunión, y fruto de la discusión, finalmente surgió un documento de consenso, avalado por los asistentes, llamado “iPor qué la endometriosis infiltrativa profunda debe ser considerada como una enfermedad distinta a la endometriosis peritoneal?" Este documento pretende sentar una posición sobre el tema específico e informar a los especialistas acerca de esta patología especialmente retadora y compleja que aqueja a numerosas pacientes en la práctica.

De esta reunión salieron varias conclusiones y recomendaciones, de las que quiero destacar las siguientes:

- La endometriosis infiltrativa profunda es una entidad diferente a la endometriosis peritoneal u ovárica.
- Su diagnóstico y su abordaje terapéutico y quirúrgico difieren ostensiblemente del que se realiza para la enfermedad peritoneal.

- Las cirugías requeridas para el manejo adecuado de pacientes con endometriosis infiltrativa profunda son procedimientos catalogados a nivel mundial como de alta complejidad, con una morbilidad intra y posoperatoria considerables, que de preferencia deben ser realizados por laparoscopia, en centros de referencia y con el concurso, en muchas ocasiones, de otras especialidades.

- Dichas cirugías no son homologables en riesgo quirúrgico, complejidad, necesidad de equipamiento y requerimiento de otros especialistas con ninguno de los procedimientos que fueron recientemente aprobados por la Comisión de Regulación en Salud (CRES) para el Plan Obligatorio de Salud (POS).

Publicamos hoy en nuestra Revista Colombiana de Obstetricia y Ginecología el documento definitivo acerca de este tema en particular, y queremos compartirlo con todos los lectores de este número.

Quiero agradecer el esfuerzo de todos los participantes en esta reunión de consenso, especialmente al doctor José Fernando De Los Ríos Posada y a su grupo de trabajo por el aporte y la labor dedicada a culminar con éxito este documento.

\section{Juan Diego Villegas-Echeverri, MD}

Presidente Fecolsog 2012-2014 